\title{
Elastomagnetic nanofiber wires by magnetic field assisted electrospinning
}

\author{
V. Guarino ${ }^{1}$, V. Iannotti ${ }^{2}$, G. Ausanio ${ }^{2}$, L. Ambrosio ${ }^{1}$, L. Lanotte Li, $^{1}$ \\ ${ }^{1}$ Institute of Polymers, Composites and Biomaterials (IPCB) National Research Council of Italy, Mostra d'Oltremare Pad. \\ 20, V.le J.F.Kennedy 54, I-80125 Naples, Italy \\ ${ }^{2}$ CNR-SPIN and Department of Physics 'E. Pancini', University of Naples Federico II, Piazzale V. Tecchio 80, I-80125 \\ Naples, Italy
}

Received 9 October 2018; accepted in revised form 5 December 2018

\begin{abstract}
Magnetic field assisted electrospinning is supplemented by conductive sheets that envelop the magnets and have the same potential as the deposition electrode. By optimizing the experimental conditions, it is possible to produce wires made of polymer nanofibers that incorporate longitudinally oriented magnetic particles. The morphological and magnetic characterizations confirm the preferential orientations. The new nanofiber wires are easily aligned along the maximum intensity line of the applied magnetic field. Moreover, the nanostructured wires have high longitudinal elastomagnetic strain and high transversal deflection as a response to magnetic field stimuli. Therefore, these new threadlike aggregates of magnetic nanofibers could be very appealing for application in all microelectronic or biomedical devices whose functionality requires orientation or deformation.
\end{abstract}

Keywords: smart polymers, biocompatible polymers, magnetic field assisted electrospinning, polymer-matrix nanocomposites, elastomagnetism

\section{Introduction}

In the recent years, innovative electrospun nanocomposites have been produced for photocatalytic, conductive, mechanical and biomedical applications [15]. At the same time, several improvements of the standard electrospinning process have been performed to achieve specific objectives, such as tri-axial processing [6], temperature control [7, 8], double-switching voltage [9], stepped airflow coupled to friction twisting [10] and bubble electrospinning [11].

Among the various techniques used to direct the electrospinning process to particular purposes, an important role was played by the Magnetic Field Assisted Electrospinning (MFAE) which was directed to the fabrication of polymeric fibers loaded with magnetic particles. MFAE has been effective in controlling the position of particles [12] or improving the jet stability during deposition [13-14] and, in particular, for producing well-aligned composite nanofibers, such as polysulfonamide [15], Ag/PVP [16] and $\mathrm{Fe}_{3} \mathrm{O}_{4}[17-19]$ in different polymer matrices.

Although two separate conductors used as a substrate can give an alignment of the fibers by electrostatic interaction [20], starting from one of the pioneering works on magnetic field assisted electrodeposition it was emphasized that the magnetic field is actually more effective in aligning the fibers in parallel arrays [21]. Models and experiments demonstrate that the magnetic field application is effective on jet stability and nanofiber alignment even if filling particles are not present or are not magnetic [2226]. In these cases, the effects of the presence of magnets are mainly attributed to the force applied by the magnetic field on the polarized jet in movement

${ }^{*}$ Corresponding author, e-mail: lanotte@fisica.unina.it

(C) BME-PT 
- considered as an electric current - and to the modification of the electric field itself. Recently, the studies have been extended to the configuration of a magnetizing field parallel to the liquid jet vertical axis or even transversal but produced by concordant magnetic poles [27, 28]. In particular, compared to other techniques useful to obtaining aligned nanofibers, such as the bubble electrospinning [11, 29], when the polymer fibers are loaded by magnetic nanoparticles, the MFAE has the advantage of being able to also induce pre-orientation of the magnetic particles by means of the unidirectional magnetic field applied during the growth of the fibers [30,31].

Herein, starting from experimental conditions used in previous studies [21, 29], substantial improvements have been performed - both in experimental configuration and in electrospinning solution - to obtain narrower membranes up to produce fibers threads that incorporate preferentially oriented magnetic nanoparticles (MNPs). The proposed experimental set-up introduces fundamental novelties with respect to the previous arrangements used for MFAE. In particular, the action of an oriented additive electrostatic field was coupled to that of an oriented magnetic field produced by two parallel $\mathrm{NdFeB}$ magnets, with a suitable distance between them. The additive electric field was produced using - for the first time in literature - an envelope around the magnets made by an aluminum sheet - at fixed electric potential and having function of collector and electrode (as described in detail in the next section) -. In comparison to the previous investigations, another substantial difference is to have progressively increased the volume fraction of the particles in the used polymer/ MNPs solution until to obtain a magnetic interaction that attracts the nanofibers towards the line of force of the maximum magnetic field, thus achieving - for the first time by MFAE - the formation of a filiform agglomerate of elctrospun fibers.

The final aim was to obtain elastomagnetic samples to develop new micro-devices able to orient or deform under the application of moderate external magnetic fields that can open several applications as smart biological tissue, electrical micro-switch and sensors (as detailed in discussion in Section 3).

\section{Materials, methods and instrumentation}

The solution to be electrospun was prepared using Polycarbonate-urethane (PCU) as polymer matrix and Nickel nanoparticles (99,99\% Aldrich Chemical) with a size between 20 and $100 \mathrm{~nm}$ as filler. The NPs size has been selected to improve the incorporation in sub-micrometric fibers, preserving a considerable magnetic moment, in order to confer high elastomagnetic sensitivity, similar to that previously obtained for higher size devices [31-34]. Different magnetic materials have been used to specific purposes (for example $\mathrm{Fe}_{3} \mathrm{O}_{4}$ [35-36]), but for the objectives of the present investigation, since elastomagnetic performance should be addressed, the Nickel appears preferable as magnetic filler material. This not only because of the previous investigations already cited [31-33], which demonstrate its good performance, but mainly because the use of the same particle allows a direct comparison with the elastomagnetic response already detected in similar Ni/polymer composites $[34,37]$. Furthermore, the PCU was chosen because it is widely used for the fabrication of implantable devices (i.e. vascular grafts, artificial heart components) $[38,39]$ and for all the biomedical applications that require high biocompatibility and a superior mechanical response in terms of elongation, flexibility, and chemical stability under aggressive microenvironments [40]. This is due to the presence of strong intermolecular bonds with polycarbonate polyol, which makes them highly resistant to biodegradation and hydrolysis [41].

Initially, Corethane, $(15 \% \mathrm{w} / \mathrm{v})$ was dissolved into a Tetrahydrofuran/Dimethylformamide (THF/DMF) (7:3) until homogeneity was achieved. Then, the Ni nanoparticles - volume fraction $(\mathrm{V} \%)$ from 0 to $12 \%$ - were added and mixed for approx. 20 minutes, thus obtaining a homogeneous viscous solution. The solution was placed in a $5 \mathrm{ml}$ plastic syringe connected to an 18 Gauge needle.

A standard equipment (Nanon01, MECC, Japan) was used for basic electrospinning setting. The apparatus has been configured to direct the liquid jet along a vertical axis, by controlling voltage, flow rate, translation motion rate of the spinneret, and distance between needle and collector. Moreover, two $\mathrm{NdFeB}$ permanent magnets $\left(30 \times 30 \times 6 \mathrm{~mm}^{3}\right)$ were integrated to the collector as shown in Figure 1 in order to produce a magnetic field transversal to the liquid jet vertical axis $x$. In the figure, $\Phi$ is the syringe needle from which the solution flows at $2 \mathrm{ml} / \mathrm{h} ; v=$ needle speed during its horizontal displacement $=1-2 \mathrm{~mm} / \mathrm{s}$; $\mathrm{V}=$ generator of constant potential difference between needle and collector plane $(17 \mathrm{kV}) ; \mathrm{AF}=$ aluminium sheet around the magnets; $\mathrm{M}_{1}$ and $\mathrm{M}_{2}=$ 


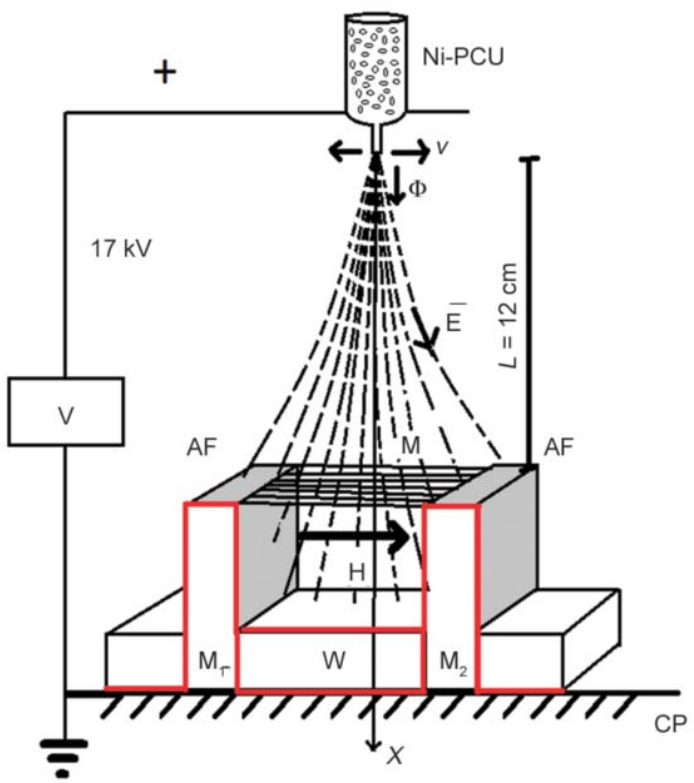

Figure 1. Experimental scheme of the apparatus used for electrospinning assisted by magnetic field and parameters controlled during deposition conditions (meaning of the symbols as indicated in the text).

$\mathrm{NdFeB}$ permanent magnets; $\mathrm{W}=$ wooden container for magnets; $\mathrm{CP}=$ base conductive plate of the manifold; $\mathrm{H}=$ magnetic field main line of force; $\mathrm{E}=$ electric field lines; Ni-PCU = polymer solution with homogeneously dispersed Ni MNPs; $\mathrm{M}=$ deposited nanofibers membrane; $L=$ distance between the jet emitter and the upper part of the aluminium sheets where the membrane of nanofibers is deposited.

Similar arrangements have been used in previous studies [21, 24, 29] to perform fibers electrospinning both in a modified electric field and in a transverse magnetic field. In this case, magnets are blocked by a wooden base plate $\mathrm{W}$ at a distance of $2.5 \mathrm{~cm}$, and emerging at $1.5 \mathrm{~cm}$ from the base. The peculiarity of this device consists in the presence of a thin aluminum sheet (red in Figure 1), which covers each magnets and goes down to the base to come in contact with the flat conducting electrode (CP) (see also image in Figure 2). The aluminium foil was used to stabilize the electric field configuration, with the main lines of force directed on the two upper faces of the aluminium sheets, thus cooperating with the magnetic field for the fibers deposition on the horizontal plane passing through the upper surfaces of the magnets.

Collected nanofiber assembly was investigated morphologically by SEM microscopy under low vacuum conditions (QuantaFEG200, FEI, The Netherlands) and characterized in its salient magnetic properties

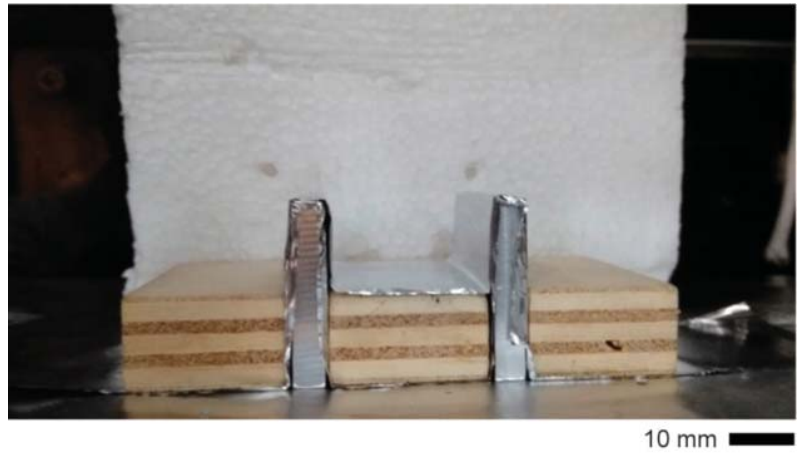

Figure 2. Detail of the collector system with magnets and aluminium foil.

by magnetization cycles detected by vibrating sample magnetometry (Maglab9T, Oxford Instrument, UK, VSM). In order to demonstrate the ability of the threadlike samples to orient along the force line of the external magnetic field or to have elastomagnetic strains, the orientation and the deformation induced by a magnetizing field was investigated in the case of wires clamped at one end or both the ends: it will be easy to understand the simple experimental setup from the figures in Section 3.

\section{Results and discussion}

The nanofibers production was initially performed with a volume percentage of MNPs equal to $3 \%$. The tension has been fixed at $17 \mathrm{kV}$, as well as the distance between the magnets $(25 \mathrm{~mm})$ and the feed rate $(2 \mathrm{~mm} / \mathrm{s})$. By changing the distance $L$ between the jet emitter and the top of the aluminium collector sheets, we determined the best value $(12 \mathrm{~cm})$ at which a well aligned membrane of fibers grows between the magnetic blocks, confining itself between the surfaces of the top part of the aluminum foil.

Then the volume fraction of the magnetic particles was changed from 0 to $12 \%$, at a fixed value of the other experimental conditions specified above. By increasing $\mathrm{V} \%$, the membrane width is reduced from $12 \mathrm{~mm}(V \%=0 \%)$ to $6 \mathrm{~mm}(V \%=12 \%)$. In agreement with previous investigation, the membrane is formed even when MNPs are not present. However, when MNPs are incorporated, the fibers are much more aligned to the main axis of the magnetizing field as reported by SEM images (Figure 3).

To obtain a tighter deposit, fixed the percentage of magnetic charge volume at $V \%=12 \%$, the jet displacement speed was reduced from $2 \mathrm{~mm} / \mathrm{s}$ to $1 \mathrm{~mm} / \mathrm{s}$. In this conditions, Figure 4a shows nanofibers which progressively approach one another to form a tape (Figure 4a, above) and finally a wire (Figure 4a, 


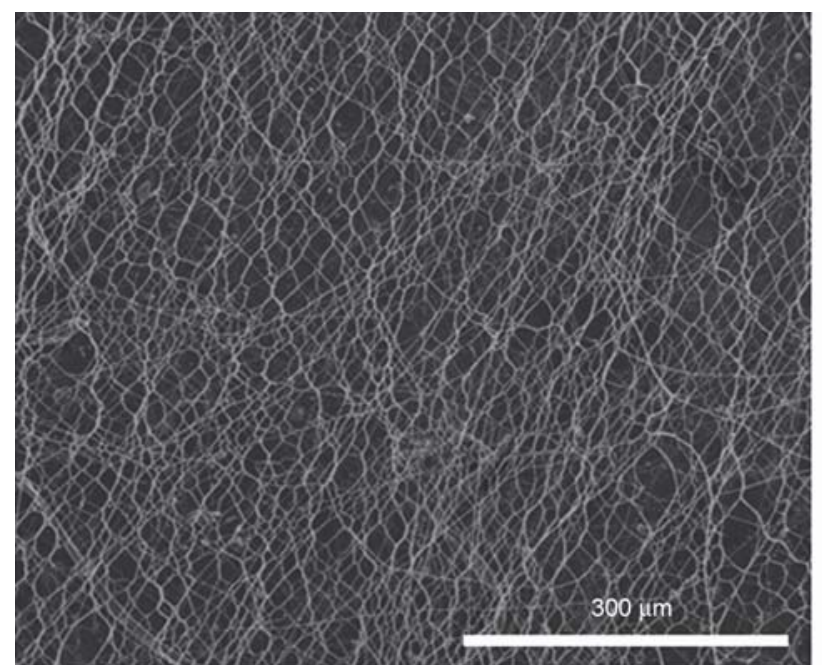

a)

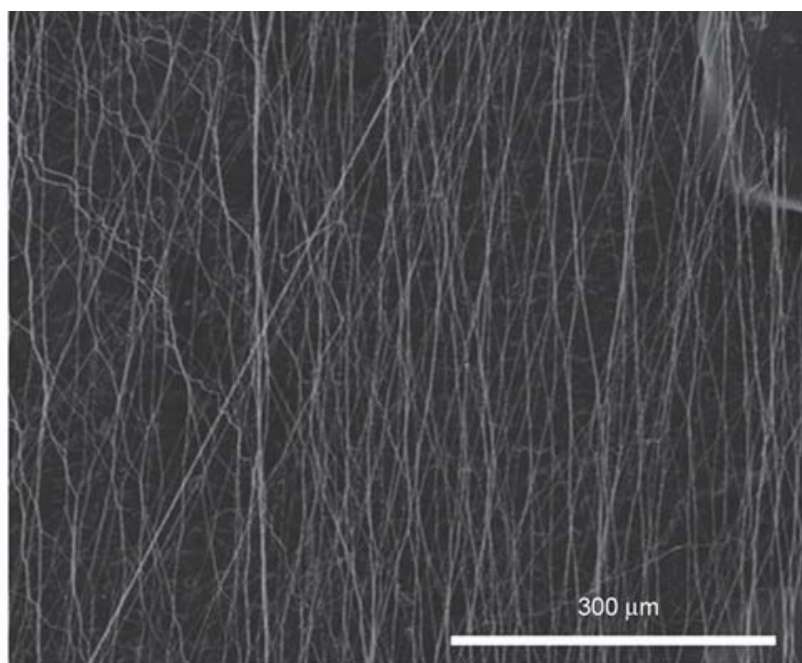

Figure 3. PCU electrospun fibers: not loaded (on the left, (a), $V \%=0 \%$ ) and loaded with MNPs (on the right, (b), $V \%=8 \%$ ) - Scale bar $300 \mu \mathrm{m}$.
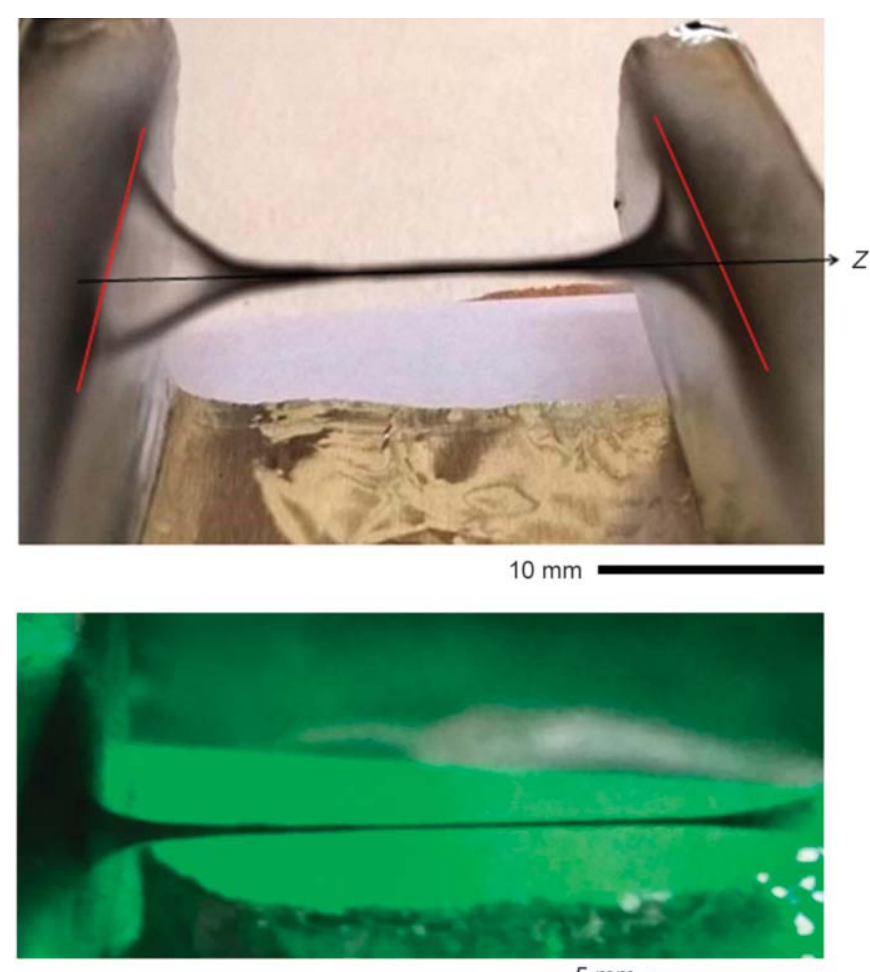

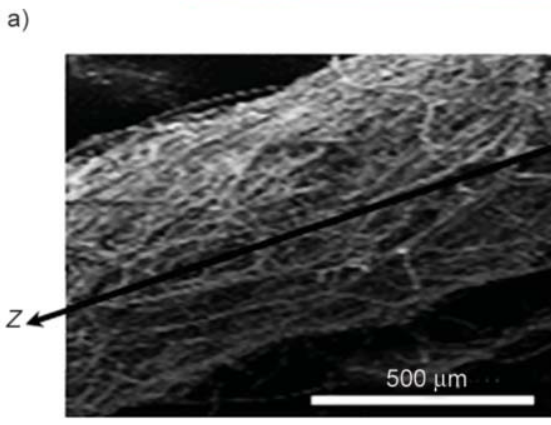

b)

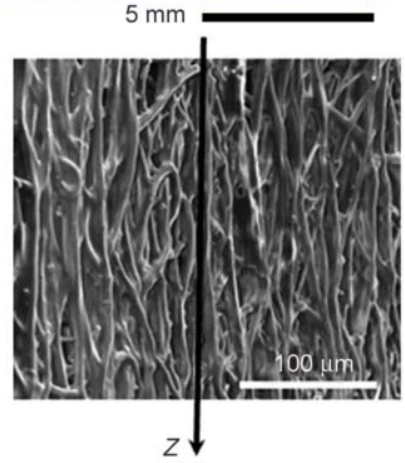

Figure 4. a) Fibers during deposition under the attractive effect of the forces produced on the nanoparticles by the magnetic field gradient transverse to the $z$-axis (MNPs volume percentage $12 \%$ and $v=1 \mathrm{~mm} / \mathrm{s}$ ). Image above was made after $60 \mathrm{~s}$ from the deposition start, while image below was obtained after $180 \mathrm{~s}$. b) SEM images of the final nanofiber wire at different magnitude. 
below) under the attractive effect of the forces produced on the nanoparticles by the magnetic field gradient transverse to the $z$-axis. When the MNPs volume content is lower $(0 \%<V \%<8 \%)$ and speed rate higher $(2 \mathrm{~mm} / \mathrm{s})$ the nanofibers would have formed a membrane covering the area between the red lines reported in the image at the top of the Figure 4a.

The SEM images in Figure $4 \mathrm{~b}$ show a section of the final filiform nanofiber agglomerate (on the left) and a magnification of it (on the right) where it is possible to see that the densely packed fibers maintain in the wire a preferential longitudinal orientation.

According to previous investigations [24, 27, 28], even in absence of MNPs, fiber membranes are formed due to the Lorentz forces on jet streams during flight, thus improving stability and localization of the deposited fibers. When MNPs are added, new important physical phenomena occur: (i) the formation of a magnetic moment in each particle due to magnetization and the consequent arising of a mechanical moment which tends to orient them along the lines of force of the magnetic field; (ii) the activation of dipolar attraction forces, which arise between the particles themselves and increase with their density. Undoubtedly these effects help the formation of a membrane with aligned nanofibers (Figures 3). But when particles concentration increases and the deposition process takes place more slowly, the forces produced on the MNPs, due to magnetic field gradient, attract

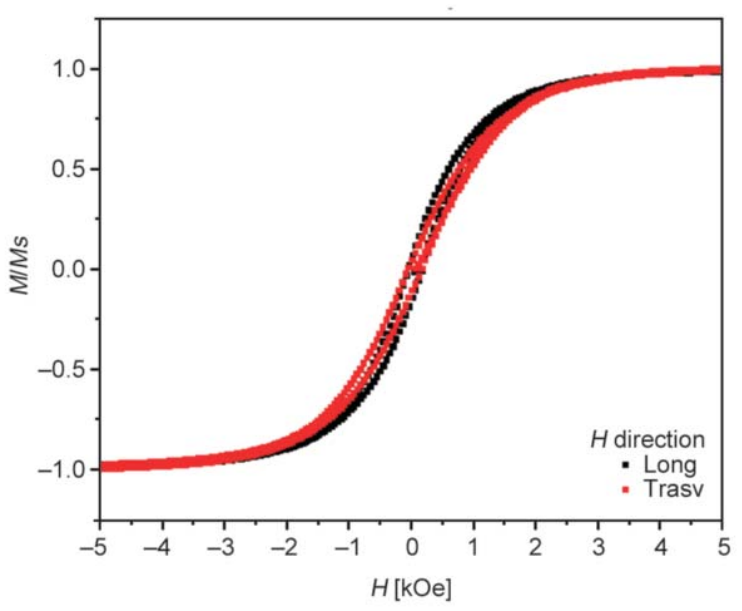

Figure 5. Comparison of normalized magnetization cycles, measured with a magnetizing field $\mathrm{H}$ applied parallel (Long) and orthogonal (Trasv) to the nanofibers wire axis: the longitudinal magnetization of the MENW approaches the saturation at a magnetizing field value lower than that of transversal magnetization - for increasing $\mathrm{H}$ the black curve increases faster than the red one - (MNPs volume percentage $12 \%$ and $v=1 \mathrm{~mm} / \mathrm{s}$ ). the fibers towards the $z$-axis, overcoming the tensile forces in the fibers: nanofibers incline up to form a filiform deposit along the line of maximum intensity of the magnetic field in the deposition plane (Figures 4). This qualitative description justifies the formation of threadlike aggregates, in the presence of a magnetic field, at high particles concentration and at low process velocity.

The proof of the NPs magnetic moment preferential orientation within the magnetic electrospun nanofibers wire (MENW) can be obtained by comparing the longitudinal magnetization cycle with respect to the transverse one. In our case, a preferential orientation of the main geometric axis of the NPs should not be high because the Ni MNPs have low shape anisotropy (pseudo-spherical shape [33, 42]). Taking this into account, Figure 5 clearly shows that longitudinal magnetization (black curve) is slightly easier than the transverse one (red curve).

\section{Aligning and strain effects of magnetization in MENWs}

The peculiar morphology and magnetic constitution of MENWs allow very interesting applications for microelectronic and biomedical devices. In particular, in this section we show two salient properties in view of the aforementioned applications: $1^{\text {st }}$ the ability of the nanofibers wire to orientate according to the external magnetic field; $2^{\text {nd }}$ the giant deflection and the longitudinal strain induced by a moderate external magnetic field.

The first property is shown in Figure 6. A nanofibers wire (20 $\mathrm{mm}$ in length and 0.3 in diameter) clamped at one end, follows in a horizontal plane the line of force of the magnetic field of a small magnet. This effect suggests the application in microelectronics as switch or diverter activated by a moderate change in magnetic field. Really, the wire also has an increase in length from the left (A) to the right (B) position, due to the increase in intensity of the magnetic field gradient on the main force line (position B), but the elastomagnetic strain effect will be better described in the following.

Undoubtedly, the implementation of the MFAE technique reported in this work allowed to put together the peculiar properties of the obtained sample: good elasticity of the PCU matrix; high density of the incorporated magnetic nanoparticles; wire-shaped nanofiber systems; preferential longitudinal magnetization. Just the coupling of these properties is the 


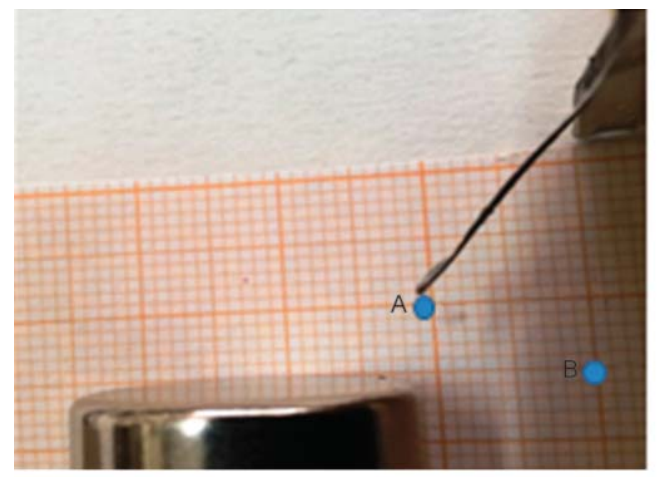

a)

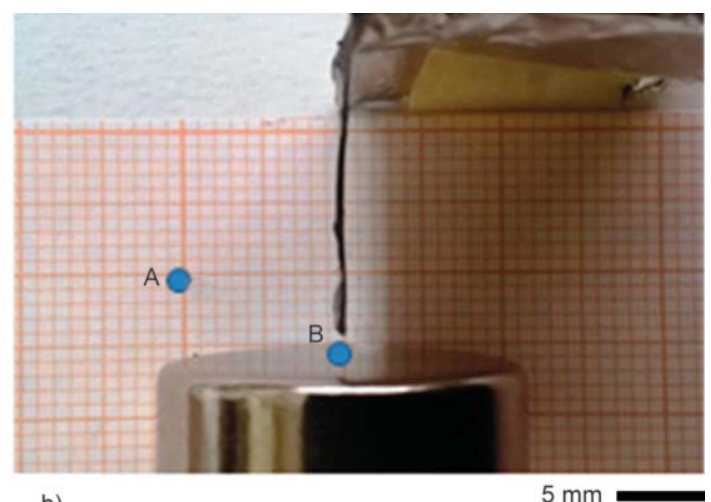

b)

$\mathrm{mm}$

Figure 6. Change of alignment axis of a MENW by moving a commercial magnet: on the right (b) it is shown the nanofiber wire aligned along the main axis of a magnet; on the left (a) it is shown the rotation of about $45^{\circ}$ induced by a $13 \mathrm{~mm}$ translation of the magnet axis. The potential fallout in the application for a magnetic field control of an electric diverter (from connector ' $\mathrm{A}$ ' to ' $\mathrm{B}$ ') is evident.

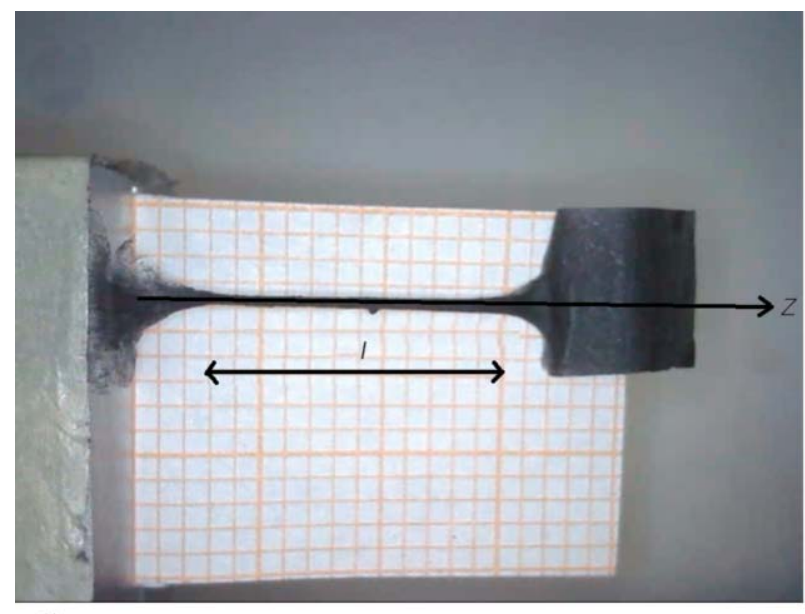

a)

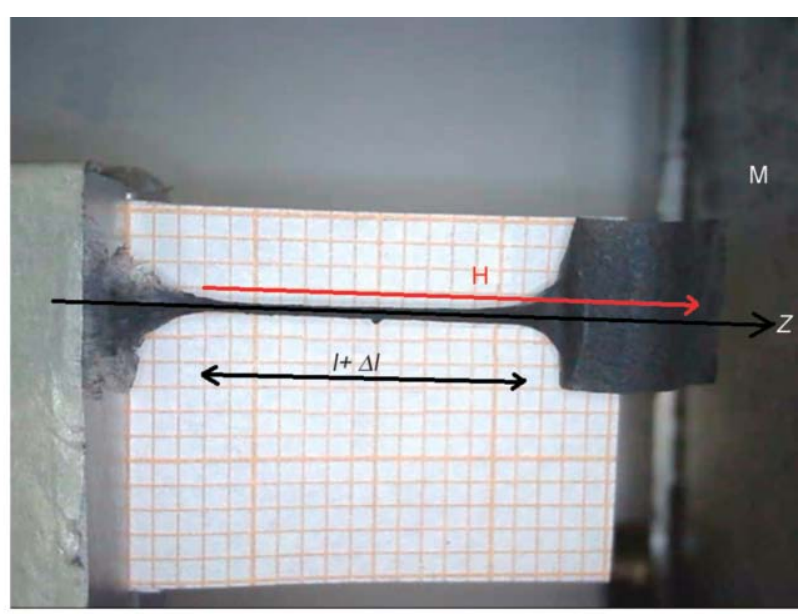

b)

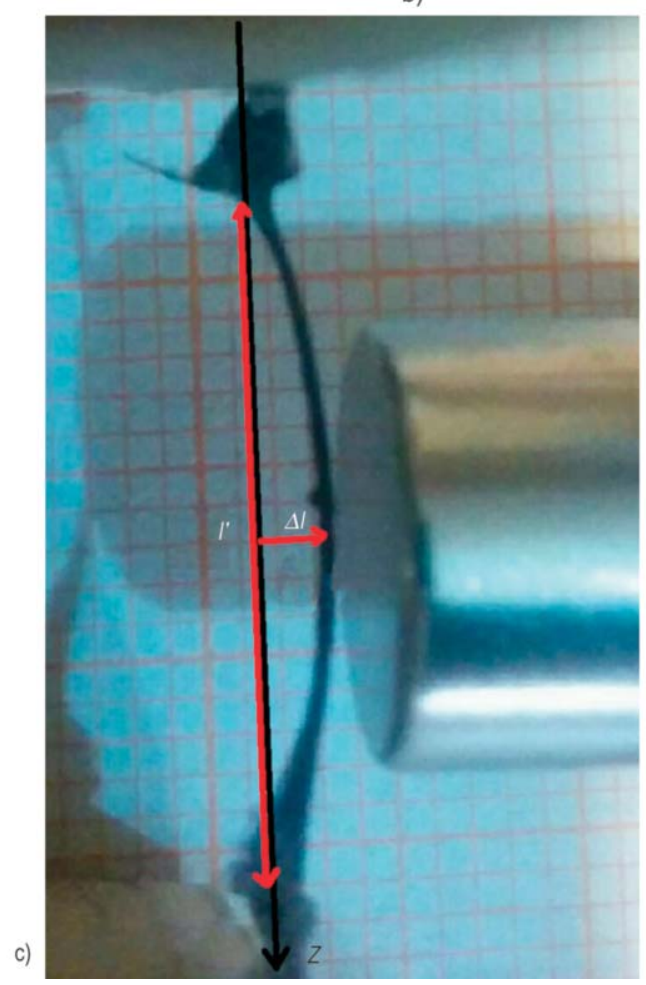

Figure 7. a) and b) Longitudinal strain of a MFAE fibers wire - clamped at the left end - under the action of longitudinal magnetic field $\mathrm{H}$ in a horizontal plane. c) Horizontal deflection of a nanofibers ribbon - clamped at both the ends - under a transversal magnetization. 
prerequisite for providing a very high direct elastomagnetic effect: a great strain produced by magnetization [42]. To verify this expectation, the new MENWs were subjected to two fundamental tests: evaluation of longitudinal strain induced by longitudinal magnetization - in a horizontal plane - in the case of a sample clamped at an end (Figures 7a and 7b); determination of the deflection produced by a transverse magnetizing field in a horizontal plane, when a MENW is bound at both the ends (Figure 7c).

Figure 7a shows a sample lying on a horizontal plane: on the left side (clamped end), it is kept attached to the aluminum sheet that cover the magnets during the deposition, while it is peeled off from the right end. The wider regions (at both ends), which are deposited directly on the aluminum, practically retain the width of the membrane obtained in the first stage, before the progressive aggregation. The effective length of the wire-like sample is $l=12 \mathrm{~mm}$. In Figure $7 \mathrm{~b}$, the effect of the application of a longitudinal magnetic field $\mathrm{H}$, produced by the NdFeB magnet (M) is shown. An elongation $(\Delta l=1 \mathrm{~mm})$ is clearly deduced.

Carefully observing Figures $7 \mathrm{a}$ and $7 \mathrm{~b}$, it is noteworthy to deduce that the sample strain concerns only the nanofiber wire and not the regions on the ends of the sample (these larger extreme regions keep their length unaltered). Therefore, the relative longitudinal elastomagnetic strain of the MENW is $\Delta l / l=$ $1 \mathrm{~mm} / 12 \mathrm{~mm} \approx 8 \cdot 10^{-2}$.

The MENWs ability to deflect under the action of a transverse field is illustrated in Figure 7c. The filiform sample, initially stretched along the $z$ axis, under the transverse field of a small $\mathrm{NdFeB}$ magnet has the deflection shown in Figure 7c, which corresponds to a maximum displacement $\Delta l$ along the central axis. The ratio between the maximum displacement and the total initial length is $\Delta l / l^{\prime}=$ $2 \mathrm{~mm} / 20 \mathrm{~mm}=10^{-1}$.

The possibility of producing different types of nanofiber wires, able of a magnetically induced giant relative deformation, is very promising in view of their functionalization in those conditions where the filiform structure can lead to advantages. In fact, on the basis of recent bibliography, MENWs development seems to open renewals and finalizations for biomedical applications [43-46], sensing devices [47-50], electromagnetic components [51,52], absorbers [53, 54], tissue engineering $[7,55,56]$ and, in particular, to biocompatible components sensitive to external stimuli in order to regenerate or to activate the contraction and dilatation of tendons and muscles that have lost their functionality [57-61].

\section{Conclusions}

Based on previous magnetic field assisted electrospinning studies, we performed some experimental upgrades to stabilize the force lines of electric and magnetic fields. In the new experimental conditions, the deposition of PCU solutions, enriched with Nickel nanoparticles, confirms the ability to form aligned nanofibers functionalized by the presence of magnetic particles. Furthermore, we have shown for the first time that this technique can be successfully used to fabricate wires made of packed nanofibers densely filled with longitudinally oriented magnetic nanoparticles. These innovative MENWs are particularly suitable to be aligned along the maximum intensity lines of the applied magnetic field. Above all, the sum of elasticity, shape and easy longitudinal magnetization, forms the basis for truly remarkable elastomagnetic properties. Compared to previous works on similar systems, longitudinal strain and transversal deflection, obtained by direct elastomagnetic effect, present very high values. Accordingly, our recent investigation [37] on the deflection of a nanofiber skin - fabricated by peeling away from the substrate a magnetic nanofiber mat, and then wrapping magnetic nanofiber together - exhibited a maximum $\Delta l / l$ of less than $2 / 3$ of that measured here. On the other hand, the longitudinal relative elastomagnetic strain was generally well below $10^{-2}$ [34], while in MENWs it approaches $10^{-1}$. These results, together with the compatibility of the PCU with the biological environment, make the new MENWs attractive for biomedical applications, such as stimulators or deformation actuators (for example in artificial tendons). Furthermore, the miniaturization of the illustrated effects, up to the nanoscale, seems to be reasonable and above all attractive for new sensors devices, nanoelectronics and biomedicine.

\section{References}

[1] Zhang L., Yu W., Han C., Guo J., Zhang Q., Xie H., Shao Q., Sun Z., Guo Z.: Large scaled synthesis of heterostructured electrospun $\mathrm{TiO}_{2} / \mathrm{SnO}_{2}$ nanofibers with an enhanced photocatalytic activity. Journal of the Electrochemical Society, 164, H651-H656 (2017).

https://doi.org/10.1149/2.1531709jes 
[2] Zhang L., Qin M., Yu W., Zhang Q., Xie H., Sun Z., Shao Q., Guo X., Hao L., Zheng Y., Guo Z.: Heterostructured $\mathrm{TiO}_{2} / \mathrm{WO}_{3}$ nanocomposites for photocatalytic degradation of toluene under visible light. Journal of the Electrochemical Society, 164, H1086-H1090 (2017). https://doi.org/10.1149/2.0881714jes

[3] Guo Y., Xu G., Yang X., Ruan K., Ma T., Zhang Q., Gu J., Wu Y., Liu H., Guo Z.: Significantly enhanced and precisely modeled thermal conductivity in polyimide nanocomposites with chemically modified graphene via in situ polymerization and electrospinning-hot press technology. Journal of Materials Chemistry C, 6, 30043015 (2018).

https://doi.org/10.1039/C8TC00452H

[4] He Y., Yang S., Liu H., Shao Q., Chen Q., Lu C., Jiang Y., Liu C., Guo Z.: Reinforced carbon fiber laminates with oriented carbon nanotube epoxy nanocomposites: Magnetic field assisted alignment and cryogenic temperature mechanical properties. Journal of Colloid and Interface Science, 517, 40-51 (2018).

https://doi.org/10.1016/j.jcis.2018.01.087

[5] Soares R. M. D., Siqueira N. M., Prabhakaram M. P., Ramakrishna S.: Electrospinning and electrospray of bio-based and natural polymers for biomaterials development. Materials Science and Engineering: C, 92, 969 982 (2018).

https://doi.org/10.1016/j.msec.2018.08.004

[6] Yang Y., Li W., Yu D-G., Wang G., Williams G. R., Zhang Z.: Tunable drug release from nanofibers coated with blank cellulose acetate layers fabricated using triaxial electrospinning. Carbohydrate Polymers, 203, 228 237 (2019).

https://doi.org/10.1016/j.carbpol.2018.09.061

[7] Liu D., Zhang C., Dong G., Xu C., Liu D., Lv Y., Zhon B., Wang B.: Temperature-controlled electrospinning of EVOH nanofibre mats encapsulated with $\mathrm{Ag}, \mathrm{CuO}$, and $\mathrm{ZnO}$ particles for skin wound dressing. Materials Research Express, 6, 015007/1-015007/11 (2019). https://doi.org/10.1088/2053-1591/aae467

[8] Xu H., Bronner T., Yamamoto M., Yamane H.: Regeneration of cellulose dissolved in ionic liquid using laserheated melt-electrospinning. Carbohydrate Polymers, 201, 182-188 (2018).

https://doi.org/10.1016/j.carbpol.2018.08.062

[9] Wu Y-K., Wang L., Fan J., Shou W., Liu Y.: A doubleswitching voltage: Controlling multiple jets in electrospinning. Materials Letters, 233, 359-362 (2018).

https://doi.org/10.1016/j.matlet.2018.09.050

[10] Zhou Y., Wang H., He J., Qi K., Ding B., Cui S.: Novel method for preparation of continuously twisted nanofiber yarn based on a combination of stepped airflow electrospinning and friction twisting. Journal of Materials Science, 53, 15735-15745 (2018). https://doi.org/10.1007/s10853-018-2725-2

[11] Yu L., Shao Z., Xu L., Wang M.: High throughput preparation of aligned nanofibers using an improved bubbleelectrospinning. Polymers, 9, 658/1-658/9 (2017). https://doi.org/10.3390/polym9120658
[12] Chung M., Lan J. W., Chang L. K., Suen T. W., Cheng S. H.: Control of nanoparticle on nanofiber via magnetic electrospinning. in 'Proceeding of Conference and Expo Nanotech, Houston, USA', 180-182 (2009).

[13] Ren Z-F., Liu B-Z., Liu G-Q., Kang Y-X., Fan H-Y., Li H-M.: Effect of magnetic force on stability of the electrospinning process. The Journal of the Textile Institute, 101, 571-574 (2010).

https://doi.org/10.1080/00405000802605072

[14] Xu L., Wu Y., Nawaz Y.: Numerical study of magnetic electrospinning processes. Computers and Mathematics with Applications, 61, 2116-2119 (2011).

https://doi.org/10.1016/j.camwa.2010.08.085

[15] Liu L., Zhou J., Hung X., Xiao C.: Preparation of aligned polysulfonamide nanofibers by magnetic electrospinning. Advanced Materials Research, 332-334, 363-366 (2011).

https://doi.org/10.4028/www.scientific.net/AMR.332-334.363

[16] Zhang C-L., Lv K-P., Hu N-Y., Yu L., Ren X-F., Liu S-L., Yu S-H.: Macroscopic-scale alignment of ultralong ag nanowires in polymer nanofiber mat and their hierarchical structures by magnetic-field-assisted electrospinning. Small, 8, 2936-2940 (2012).

https://doi.org/10.1002/smll.201201353

[17] Wang H., Tang H., He J., Wang Q.: Fabrication of aligned ferrite nanofibers by magnetic-field-assisted electrospinning coupled with oxygen plasma treatment. Materials Research Bulletin, 44, 1676-1680 (2009).

https://doi.org/10.1016/j.materresbull.2009.04.006

[18] Sánchez J. A. G., Furlan R., Valle R. L., Valle P., da Silva A. N. R.: Influence of a magnetic field in the electrospinning of nanofibers using solutions with PVDF, DMF, acetone and $\mathrm{Fe}_{3} \mathrm{O}_{4}$ nanoparticles. in ' $28^{\text {th }}$ Symposium on Microelectronics Technology and Devices (SBMicro 2013), Curitiba, Brazil' 1-3 (2013).

https://doi.org/10.1109/SBMicro.2013.6676143

[19] Sánchez J. A. G., Furlan R., López R., Fachini E., da Silva A. N. R.: Piezoelectric effect in nanofibers deposited with magnetic field assisted electrospinning using solutions with PVDF and $\mathrm{Fe}_{3} \mathrm{O}_{4}$ nanoparticles. in '2014 $29^{\text {th }}$ Symposium on Microelectronics Technology and Devices (SBMicro), Aracaju, Brazil' 1-3 (2014). https://doi.org/10.1109/SBMicro.2014.6940128

[20] Li D., Wang Y., Xia Y.: Electrospinning of polymeric and ceramic nanofibers as uniaxially aligned arrays. Nano Letters, 3, 1167-1171 (2003).

https://doi.org/10.1021/n10344256

[21] Yang D., Lu B., Zhao Y., Jiang X.: Fabrication of aligned fibrous arrays by magnetic electrospinning. Advanced Materials, 19, 3702-3706 (2007). https://doi.org/10.1002/adma.200700171

[22] Mey L., Han R., Fu Y., Liu Y.: Solvent selection for polyacrylonitrile using molecular dynamic simulation and the effect of process parameters of magnetic-field-assisted electrospinning on fiber alignment. High Performance Polymers, 27, 439-448 (2014).

https://doi.org/10.1177/0954008314555244 
[23] Xu L., Wang L., Shi N., He N.: Aligned nanofibers by magnetic-electrospinning for biomedical applications. Journal of Controlled Release, 172, e131-e132 (2013). https://doi.org/10.1016/j.jconrel.2013.08.210

[24] Liu H-Y., Xu L., Si S. N.: Effect of magnetic intensity on diameter of charged jets in electrospinning. Thermal Science, 18, 1451-1454 (2014).

https://doi.org/10.2298/TSCI1405451L

[25] Mei L-Y., Song P., Liu Y-Q.: Magnetic-field-assisted electrospinning highly aligned composite nanofibers containing well-aligned multiwalled carbon nanotubes. Journal of Applied Polymer Science, 132, 41995/141995/9 (2015).

https://doi.org/10.1002/app.41995

[26] Huang W., Jiang L., Luo J., Chen Z., Ren L., Li C.: Effect of magnetic field on stability of jet motion in electrospinning. Materials and Manufacturing Processes, 31, 1603-1607 (2016).

https://doi.org/10.1080/10426914.2015.1103858

[27] Badieyan S. S., Janmaleki M.: Nanofiber formation in the presence of an external magnetic field in electrospinning. Journal of Polymer Engineering, 35, 587-596 (2015).

https://doi.org/10.1515/polyeng-2014-0297

[28] Jayaseelan D., Biji P.: Finite element analysis of in-situ alignment of nanoparticles in polymeric nanofibers using magnetic field assisted electrospinning. Materials Research Express, 2, 095014/1-095014/9 (2015). https://doi.org/10.1088/2053-1591/2/9/095014

[29] Liu Y., Zhang X., Xia Y., Yang H.: Magnetic-field-assisted electrospinning of aligned straight and wavy polymeric nanofibers. Advanced Materials, 22, 2454-2457 (2010). https://doi.org/10.1002/adma.200903870

[30] Lanotte L., Ausanio G., Iannotti V., Luponio C. Jr.: Influence of particle pre-orientation on elastomagnetic effect in a composite material of ellipsoidal Ni microparticles in a silicone matrix. Applied Physics A, 77, 953958 (2003).

https://doi.org/10.1007/s00339-002-1939-x

[31] Ausanio G., Iannotti V., Lanotte L., Lanotte L.: Optimization of the coupling between piezoresistivity and magnetoelasticity in an elastomagnetic composite to sense a spatial gradient of the magnetic field. The European Physical Journal B, 86, 51/1-51/5 (2013).

https://doi.org/10.1140/epjb/e2012-30657-1

[32] Ausanio G., Hison C. L., Iannotti V., Lanotte L., Lanotte L.: Magneto-piezoresistance in elastomagnetic composites. Journal of Applied Physics, 110, 063903/1063903/5 (2011). https://doi.org/10.1063/1.3634120

[33] Lanotte L., Ausanio G., Iannotti V., Pepe G., Carotenuto G., Netti P., Nicolais L.: Magnetic and magnetoelastic effects in a composite material of Ni microparticles in a silicone matrix. Physical Review B, 63, 054438/1054438/6 (2001).

https://doi.org/10.1103/PhysRevB.63.054438
[34] Guarino V., Ausanio G., Iannotti V., Ambrosio L., Lanotte L.: Electrospun nanofiber tubes with elastomagnetic properties for biomedical use. Express Polymer Letters, 12, 318-329 (2018).

https://doi.org/10.3144/expresspolymlett.2018.28

[35] Wang L., Qiu H., Liang C., Song P., Han Y., Han Y., Gu J., Kong J., Pan D., Guo Z.: Electromagnetic interference shielding MWCNT-Fe $3 \mathrm{O}_{4} @ \mathrm{Ag} /$ epoxy nanocomposites with satisfactory thermal conductivity and high thermal stability. Carbon, 141, 506-514 (2019).

https://doi.org/10.1016/j.carbon.2018.10.003

[36] Li Y., Jing T., Xu G., Tian J., Dong M., Shao Q., Wang B., Wang Z., Zheng Y., Yang C., Guo Z.: 3-D magnetic graphene oxide-magnetite poly(vinyl alcohol) nanocomposite substrates for immobilizing enzyme. Polymer, 149, 13-22 (2018).

https://doi.org/10.1016/j.polymer.2018.06.046

[37] Guarino V., Branda F., Ausanio G., Iannotti V., Lanotte L., Ambrosio L.: Elastomagnetic Ni-PDMS nanofibers via coaxial electrospinning. Materials Research Express, 5, 085029/1-085029/7 (2018). https://doi.org/10.1088/2053-1591/aad31c

[38] Wijeyaratne S. M., Kannangara L.: Safety and efficacy of electrospun polycarbonate-urethane vascular graft for early hemodialysis access: First clinical results in man. The Journal of Vascular Access, 12, 28-35 (2011). https://doi.org/10.5301/JVA.2011.6278

[39] Clauser J., Gester K., Roggenkamp J., Mager I., Maas J., Jansen S. V., Steinseifer U.: Micro-structuring of polycarbonate-urethane surfaces in order to reduce platelet activation and adhesion. Journal of Biomaterials Science, Polymer Edition, 25, 504-518 (2014). https://doi.org/10.1080/09205063.2013.879561

[40] Schwartz C. J., Bahadur S.: Development and testing of a novel joint wear simulator and investigation of the viability of an elastomeric polyurethane for total-joint arthroplasty devices. Wear, 262, 331-339 (2007). https://doi.org/10.1016/j.wear.2006.05.018

[41] Christenson E. M., Dadsetan M., Wiggins M., Anderson J. M., Hiltner A.: Poly(carbonate urethane) and poly (ether urethane) biodegradation: In vivo studies. Journal of Biomedical Materials Research A, 69, 407-416 (2004). https://doi.org/10.1002/jbm.a.30002

[42] Iannotti V., Ausanio G., Lanotte L., Lanotte L.: Magneto-piezoresistivity in iron particle-filled silicone: An alternative outlook for reading magnetic field intensity and direction. Express Polymer Letters, 10, 65-71 (2016). https://doi.org/10.3144/expresspolymlett.2016.7

[43] Spagnol C., Fragal E. H., Pereira A. G. B., Nakamura C. V., Muniz E. C., Follmann H. D. M., Silva R., Rubira A. F.: Cellulose nanowhiskers decorated with silver nanoparticles as an additive to antibacterial polymers membranes fabricated by electrospinning. Journal of Colloid and Interface Science, 531, 705-715 (2018). https://doi.org/10.1016/j.jcis.2018.07.096 
[44] Song C., Wang X-X., Zhang J., Nie G-D., Luo W-L., Fu J., Ramakrishna S., Long Y-Z.: Electric field-assisted in situ precise deposition of electrospun $\gamma-\mathrm{Fe}_{2} \mathrm{O}_{3} /$ polyurethane nanofibers for magnetic hyperthermia. Nanoscale Research Letters, 13, 273/1-273/11 (2018). https://doi.org/10.1186/s11671-018-2707-y

[45] Demir D., Güreş D., Tecim T., Genç R., Bölgen N.: Magnetic nanoparticle-loaded electrospun poly( $\varepsilon$-caprolactone) nanofibers for drug delivery applications. Applied Nanoscience, 8, 1461-1469 (2018).

https://doi.org/10.1007/s13204-018-0830-9

[46] Lin J., Chen X. Y., Chen C. Y., Hu J. T., Zhou C. L., Cai X. F., Wang W., Zheng C., Zhang P. P., Cheng J., Guo Z. H., Liu H.: Durably antibacterial and bacterially antiadhesive cotton fabrics coated by cationic fluorinated polymers. ACS Applied Materials and Interfaces, 10, 6124-6136 (2018).

https://doi.org/10.1021/acsami.7b16235

[47] Maleki S., Madrakian T., Afkhami A.: Application of polyacrylonitrile nanofibers decorated with magnetic carbon dots as a resonance light scattering sensor to determine famotidine. Talanta, 181, 286-295 (2018). https://doi.org/10.1016/j.talanta.2018.01.021

[48] Hu C., Li Z., Wang Y., Gao J., Dai K., Zheng G., Liu C., Shen C., Song H., Guo Z.: Comparative assessment of the strain-sensing behaviors of polylactic acid nanocomposites: Reduced graphene oxide or carbon nanotubes. Journal of Materials Chemistry C, 5, 2318-2328 (2017).

https://doi.org/10.1039/C6TC05261D

[49] Yuan T., Qi X., Liu Z., Yang J., Guan C., Long Q., Cao J., Luo M., Yang X., Yuan L.: Humidity sensor based on micro optical fiber array fabricated by electrospinning. Optics Communication, 427, 517-521 (2018). https://doi.org/10.1016/j.optcom.2018.07.031

[50] Yang Y., Zhang Z., He Y., Wang Z., Zhao Y., Sun L.: Fabrication of $\mathrm{Ag} @ \mathrm{TiO}_{2}$ electrospinning nanofibrous felts as SERS substrate for direct and sensitive bacterial detection. Sensors and Actuators B: Chemical, 273, 600-609 (2018).

https://doi.org/10.1016/j.snb.2018.05.129

[51] Chen X., Cheng L., Li H., Barhoum A., Zhang Y., He X., Yang W., Bubakir M. M., Chen H.: Magnetic nanofibers: Unique properties, fabrication techniques, and emerging applications. Chemistry Select, 3, 9127-9143 (2018).

https://doi.org/10.1002/slct.201702480

[52] Wang Z., Wei R., Liu X.: Fluffy and ordered graphene multilayer films with improved electromagnetic interference shielding over X-band. ACS Applied Materials and Interfaces, 9, 22408-22419 (2017).

https://doi.org/10.1021/acsami.7b04008
[53] Zhu X., Tian Y., Li F., Liu Y., Wang X., Hu X.: Preparation and application of magnetic superhydrophobic polydivinylbenzene nanofibers for oil adsorption in wastewater. Environmental Science and Pollution Research, 25, 22911-22919 (2018).

https://doi.org/10.1007/s11356-018-2385-4

[54] Tuo X., Li B., Yu X., Chen C., Huang Z., Cao H., Huang Y., Li L.: Facile synthesis of magnetic polypyrrole composite nanofibers and their application in Cr(VI) removal. Polymer Composites, 39, 1507-1513 (2018).

https://doi.org/10.1002/pc.24091

[55] Zhang H., Xia J., Pang X., Zhao M., Wang B., Yang L., Wan H., Wu J., Fu S.: Magnetic nanoparticle-loaded electrospun polymeric nanofibers for tissue engineering. Materials Science and Engineering: C, 73, 537-543 (2017). https://doi.org/10.1016/j.msec.2016.12.116

[56] Balint R., Cassidy N. J., Cartmell S. H.: Conductive polymers: Towards a smart biomaterial for tissue engineering. Acta Biomaterialia, 10, 2341-2353 (2014). https://doi.org/10.1016/j.actbio.2014.02.015

[57] Mirfakhrai T., Madden J. D. W., Baughman R. H.: Polymer artificial muscles. Materials Today, 10, 30-38 (2007). https://doi.org/10.1016/S1369-7021(07)70048-2

[58] Reverchon E., Baldino L., Cardea S., De Marco I.: Biodegradable synthetic scaffolds for tendon regeneration. Muscles, Ligaments and Tendons Journal, 2, 181186 (2012).

[59] Dang T. T., Nikkhah M., Memic A., Khademhosseini A.: Polymeric biomaterials for implantable prosthesis. in 'Natural and synthetic biomedical polymers' (eds.: Kumber S. G., Laurencin C. T., Deng M.) Elsevier, Burlington, 309-331 (2014).

https://doi.org/10.1016/B978-0-12-396983-5.00020-X

[60] Abdullah S.: Usage of synthetic tendons in tendon reconstruction. in 'Proceeding of $10^{\text {th }}$ Congress of the Asia-Pacific Federation of Societies of Surgery of the Hand and the $6^{\text {th }}$ Congress of the Asia-Pacific Federation of Societies of Hand Therapists. Kuala Lumpur, Malaysia’ Vol 9(suppl.3), A68/1-A68/2 (2015).

https://doi.org/10.1186/1753-6561-9-S3-A68

[61] Kim J., Bae S-H., Kotal M., Stalbaum T., Kim K. J., Oh I-K.: Soft but powerful artificial muscles based on 3D graphene-CNT-NI heteronanostructures. Small, 13, 1701314/1-1701314/9 (2017). https://doi.org/10.1002/smll.201701314 